\title{
Self-reported sex differences in high-functioning adults with autism: a meta-analysis
}

\author{
R. L. Moseley* (D, R. Hitchiner and J. A. Kirkby
}

\begin{abstract}
Background: Sex differences in autistic symptomatology are believed to contribute to the mis- and missed diagnosis of many girls and women with an autism spectrum condition (ASC). Whilst recent years have seen the emergence of clinical and empirical reports delineating the profile of young autistic girls, recognition of sex differences in symptomatology in adulthood is far more limited.

Methods: We chose here to focus on symptomatology as reported using a screening instrument, the Ritvo Autism Asperger Diagnostic Scale-Revised (RAADS-R). In a meta-analysis, we pooled and analysed RAADS-R data from a number of experimental groups. Analysis of variance (ANOVA) searched for the presence of main effects of Sex and Diagnosis and for interactions between these factors in our sample of autistic and non-autistic adults.

Results: In social relatedness and circumscribed interests, main effects of Diagnosis revealed that as expected, autistic adults reported significantly greater lifetime prevalence of symptoms in these domains; an effect of Sex, in circumscribed interests, also suggested that males generally reported more prevalent symptoms than females. An interaction of Sex and Diagnosis in language symptomatology revealed that a normative sex difference in language difficulties was attenuated in autism. An interaction of Sex and Diagnosis in the sensorimotor domain revealed the opposite picture: a lack of sex differences between typically developing men and women and a greater prevalence of sensorimotor symptoms in autistic women than autistic men.

Conclusions: We discuss the literature on childhood sex differences in relation to those which emerged in our adult sample. Where childhood sex differences fail to persist in adulthood, several interpretations exist, and we discuss, for example, an inherent sampling bias that may mean that only autistic women most similar to the male presentation are diagnosed. The finding that sensorimotor symptomatology is more highly reported by autistic women is a finding requiring objective confirmation, given its potential importance in diagnosis.
\end{abstract}

Keywords: Sex, Gender, Self-report, RAADS-R

\section{Background}

Females with autism are historically underdiagnosed. In cognitively impaired children, autism diagnosis is currently estimated at two boys to every girl in cognitively impaired children, whereas in those who are higherfunctioning, estimates range from 5.7, 11 or 15.7 boys to every girl (see $[1,2])$. Most recently within the UK (Scotland, specifically), diagnostic ratios were put at 3.5 males to every female in autistic children and adolescents,

\footnotetext{
* Correspondence: rmoseley@bournemouth.ac.uk

Department of Psychology, Bournemouth University, Fern Barrow, Poole, Dorset BH12 5BB, UK
}

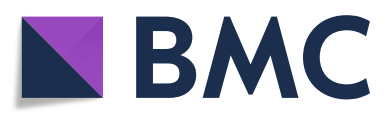

(c) The Author(s). 2018 Open Access This article is distributed under the terms of the Creative Commons Attribution 4.0 International License (http://creativecommons.org/licenses/by/4.0/), which permits unrestricted use, distribution, and

reproduction in any medium, provided you give appropriate credit to the original author(s) and the source, provide a link to the Creative Commons license, and indicate if changes were made. The Creative Commons Public Domain Dedication waiver (http://creativecommons.org/publicdomain/zero/1.0/) applies to the data made available in this article, unless otherwise stated. and two males to every female in adults [3]. A recent renostic ratio, in children, of three boys diagnosed to every girl [4]. Convincing arguments from genetic research, beyond the scope of the present article, suggest that the prevalence of autism could be genuinely lower in females $[2,5-8]$, but in so far as those who are diagnosed, diagnostic rates appear to reflect a kind of 'bimodal distribution, with the more severely impaired autistic females likely to be detected in childhood and those without intellectual disability and with subtler presentations likely to be either missed or diagnosed later in life $[1,9]$. The fact

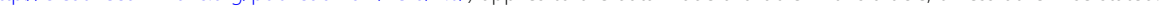


that age of diagnosis is on average later in autistic females than males corroborates the known difficulty identifying girls and women and corroborates the calls from the autistic and the scientific community for research into the female autistic phenotype $[5,10]$.

Clinical reports and empirical studies continue to crystallise the female phenotype as it appears in young girls, though it must be noted that differences in sampling techniques and methodologies make comparison of findings somewhat opaque. Several studies of early childhood suggest that differences may become more apparent with age, finding no significant differences between male and female infants and toddlers in autistic symptomatology within broad domains [11-13]. A more detailed look at each symptom category, as children age, reveals the emergence of considerable differences. With consideration of the core diagnostic impairments in social communication and interaction [14], girls with autism are believed to be equivalent to their male peers in core difficulties with social understanding [5, 15]; reports that autistic girls exhibit greater social impairment [16-18] may be subject to the fact that less severe presentations of autism (i.e. highfunctioning autism) are less likely to be recognised and thus diagnosed in girls [19-22]). The expressive behaviours of girls with autism, such as in making reciprocal conversation and displaying appropriate non-verbal behaviour and gestures, do however tend to outpass male peers [5, 23]; this is starkly illustrated by Hiller et al. [24], who found that whilst girls are more likely to use social gestures, their usage does not reflect underlying understanding. The fact that gestures may be unusually 'vivid', characterised by increased energy [23], could potentially say something of their learned nature. Young girls with autism are also known to be far more likely than boys to engage in complex imitation [24], which is problematic given the central featuring of imitative abilities in gold-standard diagnostic tests.

Autistic girls are more likely to correspond to Wing and Gould's [25] 'active but odd' category and tend away from 'autistic aloneness' [26, 27]. Indeed, where males with autism may withdraw from the more active games of their peers [24, 28], autistic girls are believed to be more socially motivated $[29,30]$ and, like non-autistic girls, to spend time chatting with friends as opposed to engaging in activities like sports or gaming [30-32]. Whilst these studies highlight similarities between autistic and non-autistic girls in female friendships, they do note that autistic girls struggle with managing conflict in relationships, and that social time is exhausting to them. This may be because, unlike autistic boys, autistic girls appear especially adept at skilfully managing social interaction through mimicking and rote-learnt strategies [24, 33, 34]. Qualitative investigation of these strategies suggest masterful adaptation where girls describe empathetic approaches as piggybacking on excellent memory and adherence to a learnt "social code" via observation and subsequent imitation [35]. Quantitative attempts to capture these abilities show a discrepancy between the scores of women on mentalising tests and core autistic traits (measuring internal disposition and core ability) and their outwards sociocommunicative performance in the Autism Diagnostic Observation Schedule (ADOS-G) [36]. The masking skills of girls and women can unfortunately confound diagnosis, as does a lack of awareness of the female autistic phenotype in professionals and the gender stereotypes which cast socially impaired girls as 'shy' and socially impaired boys as 'unresponsive' [37]. Less disruptive, with fewer externalising and more internalising problems at school age [38-41], autistic girls are more likely to be mothered or accepted by non-autistic girls as fringe members of female social groups at least until adolescence, when female friendships require considerable social adroitness [35].

Autistic girls are also less likely than boys to stand out in the diagnostic domain of restricted and repetitive interests and behaviour, where they tend to exhibit fewer classically autistic symptoms like lining objects up and fascination with small parts $[15,17,42-46]$. Indeed, fascination with small parts and mechanical objects, in early-diagnosed children, is predictive of their being male [24]. Special interests, in girls, tend to be less eccentric and more age- and gender-appropriate (for example ponies or boybands), collecting things like stickers or shells, or obsessional behaviour with toys [24] but equal to those of autistic boys (and different from non-autistic girls) in their intensity $[5,33]$. Autistic girls are more likely to engage in pretend play than autistic boys and may appear to have rich inner lives which under closer scrutiny may be seen to be extraordinarily scripted and repetitive [33, 39, 40, 47]. Sensory processing differences, which also fall within this diagnostic domain, are apparently equally apparent $[33,48]$, but research in this domain is limited; others report greater abnormalities in touch, taste and smell in autistic girls [49].

With the literature focused on childhood presentation, autistic adults are a neglected population in research and less is known about whether these sex differences in autistic symptomatology persist. Both autistic men and women differ from non-autistic adults in the attention they pay to faces [50], though interestingly this study did not replicate the trend seen in autistic males to fixate more on the mouth area [51, 52]. These three studies found abnormalities in social attention (as reflected by eye-gaze) to correlate with social competence, emotion recognition and autistic symptomatology respectively [50-52], so it is therefore perhaps unsurprising that difficulties with emotion recognition remain equally prevalent and equivalent in autistic men and women $[1,53]$, and likewise no differences were seen in empathy and systemizing, the drive to fit the world into rule-based systems $[53,54]$. This last finding is particularly note-worthy given that normative sex differences in these domains appear to be attenuated in men and women 
with autism, a finding corroborated by a large-scale survey that revealed that men and women with autism are more similar to each other than are typically developing men and women [55].

Notwithstanding these similarities, other reports suggest that autism continues to present differently in males and females once they reach adulthood. Lai et al. [53] observed lower scores for women on the sociocommunicative aspects of the ADOS-G [56], seemingly consistent with the expressive skills of autistic females mentioned above, and reports of more sensory issues. There have been some reports of advantages for autistic women over autistic men in executive function and processing speed $[1,54,57]$, which may partially explain their success in camouflage [34, 35, $58,59]$. Not all studies, however, have found differences between autistic men and women in executive function (for example, a lack of difference in response inhibition [54]): it is important to note that 'executive function', as a construct, in fact consists of multiple processes, each with distinct developmental trajectories, which are difficult to tease apart and to test in an ecologically valid way, hence the inconsistencies across autism research [60]. Indeed, some reports of sex differences in executive function in autistic children have reported patterns in the reverse, with poorer response inhibition and greater perseveration in autistic girls than boys [61, 62].

Outside of comparative tests in the laboratory, few studies have compared the real life outcomes in autistic men and women. A qualitative analysis by Baldwin and Costley [63] suggested that women might also have greater success than men in being able to study in higher education, though they also self-reported higher rates of mental illness. The same study suggested some interesting reversals of childhood trends: women were more likely than men to highlight difficulties with social interaction as the worst aspects of their employment history, were less likely to aspire to marriage or romantic relationships and more likely to prefer their own company, in contrast to the apparently higher social motivation seen in childhood. Whilst this study featured an impressive sample size, quantitative validation of these tantalising hints would be important.

A common theme throughout the limited literature in adults concerns the struggles that autistic women face in obtaining a diagnosis $[1,58,59,63]$. The implications of this difficulty are potentially immense, such that many individuals lack support and treatment for their symptomatology $[22,64]$. For this reason, the present study aimed to further the limited literature on the symptomatic differences between autistic men and women. We chose to do so utilising an established screening test which is employed in local diagnostic services in SouthWest England: the Ritvo Autism Asperger Diagnostic Scale-Revised (RAADS-R [65]). Sample size is always immensely problematic in comparing males and females with autism, given the diagnostic bottleneck which results in many more males than females being identified [22]. For this reason, we sought to supplement our own data by pooling it with that from participating researchers who had also used the RAADS-R. We thus examined self-report ratings made by autistic and nonautistic adults of symptomatology in four domains: social relatedness, circumscribed interests, language and sensorimotor abnormalities.

\section{Methods}

We adopted the two-factorial design recommended by Lai et al. [5]: by comparing autistic men and women to each other as well as to typically developing men and women, it is possible to tease out normative sex differences in cognition which may or may not be present in autism. The focus for comparison was scores in the RAADS- $R$ domains of social relatedness, circumscribed interests, sensory motor (henceforth sensorimotor) and language symptoms.

To supplement data gathered by our research group, we conducted a meta-analysis of studies which had used the RAADS-R. Below we describe our final selection of participants and the process of our meta-analysis, but details of the participant cohorts involved are given fully in Additional file 1. Ethical approval for the study was given by Bournemouth University Ethics Committee.

\section{Participants}

We obtained a total 961 datasets: 179 typically developing (TD) men, 528 typically developing women, 118 autistic men, and 136 autistic women (see Additional file 1) (Table 1). To ensure data quality, some control participants who scored particularly highly on the RAADS-R (and so might potentially be undiagnosed autistics) were removed (see Additional file 1, for details), leaving 137 TD men, 464 TD women, 118 autistic men, and 136 autistic women. In attempts to objectively create more evenly sized and agematched groups, we used freely available software [66] to reduce the number of TD females by selecting those best matched in age to the other groups. Therefore, the final participants included in our analysis were 137 TD men, 136 TD women, 118 autistic men, and 136 autistic women. Whilst significant age differences remained between all four groups $(F[3,523]=3.230, p=.022)$, no significant age differences remained in three of the four contrasts of interest for this analysis: namely, between TD men and men with autism spectrum conditions (ASC) $(p=.192)$, TD females and females with ASC $(p=.944)$, and between autistic men and women $(p=.194)$. TD women included in the study were significantly older than TD men $(t[271]=2.635, p=.009)$.

As we were unable to obtain details of IQ, we were unable to match participants in this variable; however, all individuals are assumed to be of average or above-average IQ 
Table 1 Average age in years (standard deviation in brackets) for each experimental group. The number of participants included from each source is displayed to the right

\begin{tabular}{|c|c|c|}
\hline & Age (years) & Source \\
\hline Typically developing men $(n=137)$ & $33.1(13.5)$ & $\begin{array}{l}\text { Bournemouth University }(n=30) \\
\text { Kirkovski/Fitzgerald group }(n=12) \\
\text { Libero/Kana group }(n=13) \\
\text { Schwartzman/Kapp group }(n=82)\end{array}$ \\
\hline Typically developing women $(n=136)$ & $37.4(13.8)$ & $\begin{array}{l}\text { Bournemouth University }(n=16) \\
\text { Kirkovski/Fitzgerald group }(n=4) \\
\text { Schwartzman/Kapp group }(n=116)\end{array}$ \\
\hline Autistic men $(n=118)$ & $35.3(13.4)$ & $\begin{array}{l}\text { Bournemouth University }(n=34) \\
\text { Kirkovski/Fitzgerald group }(n=13) \\
\text { Libero/Kana group }(n=5) \\
\text { Schwartzman/Kapp group }(n=84)\end{array}$ \\
\hline Autistic women $(n=136)$ & $37.5(14)$ & $\begin{array}{l}\text { Bournemouth University }(n=35) \\
\text { Kirkovski/Fitzgerald group }(n=12) \\
\text { Libero/Kana group }(n=14) \\
\text { Schwartzman/Kapp group }(n=57)\end{array}$ \\
\hline
\end{tabular}

due to the nature of the recruitment process and the studies they participated in (see Additional file 1). We do not possess details of comorbid psychiatric disorders or use of psychotropic medication for all datasets, and so cannot confirm that all participants were medication-free or without additional psychiatric conditions.

\section{Materials}

The Ritvo Autism Asperger Diagnostic Scale-Revised (RAADS-R [65]) is an 80-item self-report questionnaire recommended by the National Institute of Health and Care Excellence [67] in Great Britain to screen adults of average to above-average intelligence for an autism spectrum condition. Although it has been used in research as a self-report measure, the RAADS-R was designed to be completed in clinical settings with the assistance of a clinician. 'Diagnostic Scale' is somewhat misleading [68]: this test functions rather as a screening instrument or, as the authors intended, as just one part of a comprehensive assessment rather than a standalone diagnostic instrument. The revised version of the original scale was standardised on 201 autistic individuals (145 males) and 578 non-autistic TD (248 males), collected in nine centres on three continents, and like the original is based on diagnostic criteria for autism and Asperger syndrome in DSM-IV-TR and ICD-10 (criteria that were retained in DSM-V). In this large study, the test showed high specificity in its ability to distinguish between TD and autistic individuals whose diagnoses had been independently confirmed (no false positives). Only six of 201 autistic participants scored below 65 and were consequently unidentified (97\% sensitivity). The test also showed good test-retest reliability and high concurrent validity (95.59\%) with other popular tests for ASC such as the Social Responsiveness Scale Adult Research version [69]. It has been validated for use in other languages [70] and shortened to a 14-item version with demonstrated capacity to discriminate between ASC and some commonly comorbid psychiatric conditions [71].

The RAADS-R yields four subscales based on symptom areas from DSM-IV-TR [72] and ICD-10 [73], which themselves have high internal consistency. These domains are social relatedness (e.g. 'I often don't know how to act in social situations'), circumscribed interests (e.g. 'I only like to talk to people who share my special interests'), sensorimotor (e.g. 'I always notice how food feels in my mouth. This is more important to me than how it tastes') and language (e.g. 'I have a hard time figuring out what some phrases mean, like "you are the apple of my eye"'). Each item is scored in order of its emergence and current occurrence, with 'True now and when I was young' scored at 3; 'True only now' scored at 2; 'True only when I was younger than 16 ' scored at 1 ; and 'Never true' scored at 0 . (This scoring is reversed for negative items, such as 'I can put myself in other people's shoes').

\section{Procedure}

In order to obtain a sizeable sample, we supplemented our data with that collected by other authors in a metaanalysis [74]. Inclusion criteria were that (1) studies must include clinically diagnosed autistic and nonautistic participants, on whom the RAADS-R had been conducted; (2) participants must be adults (that is, aged 18 or above); and (3) only studies using the RAADS-R, not the original Ritvo Autism Asperger Diagnostic Scale or the newer 14-item version [71] would be included. This therefore stipulated criteria 4), that only studies occurring between 2011 (the publication of the RAADS-R) and the present year of 2017 would be included. Exclusion criteria included (1) studies involving other clinical but non-autistic populations which were being screened for autistic traits (e.g. [65, 75]); (2) studies which used the RAADS-R to assume the presence of autism but did 
not confirm the diagnosis with participants (e.g. [76]); (3) studies written in languages other than English; and 4) or reviews citing the RAADS-R which did not include actual data.

We searched three online databases (Web of Science, PubMed, Science Direct) with the search command: 'Ritvo Autism Asperger Diagnostic Scale-Revised'. We also used Google Scholar to identify all publications which had cited Ritvo et al.'s publication of their scale. With some overlap and much redundancy, we obtained 6 search results from Web of Science, 4 from PubMed, 87 from Science Direct, and 85 from Google Scholar (see Additional file 1). Sorting through these citations with our criteria in mind, we identified 16 relevant studies and contacted 8 research groups (see Additional file 1). We received useable datasets from three of these (see Additional file 1). We ensured the data was numerically coded in the same way as our own (one for female, two for male, for example) before collating it in SPSS (Statistical Programme for the Social Sciences).

Statistical analysis examined scores on the social relatedness, circumscribed interests, language and sensorimotor subscales of the RAADS-R. For each domain, separate two-way ANOVAs included between-subjects factors of Diagnosis (autistic vs. TD) and Sex (female vs. male). Interactions between Diagnosis and Sex, in this context, indicate that sex differences are attenuated or increased by the presence or lack of an autism diagnosis. The presence of an interaction thus motivated post hoc comparisons between males and females within the TD and within the autistic group.

\section{Results}

Effects of sex and diagnosis were examined for each RAADS-R domain independently and averages for each group can be seen in Fig. 1. In the social relatedness

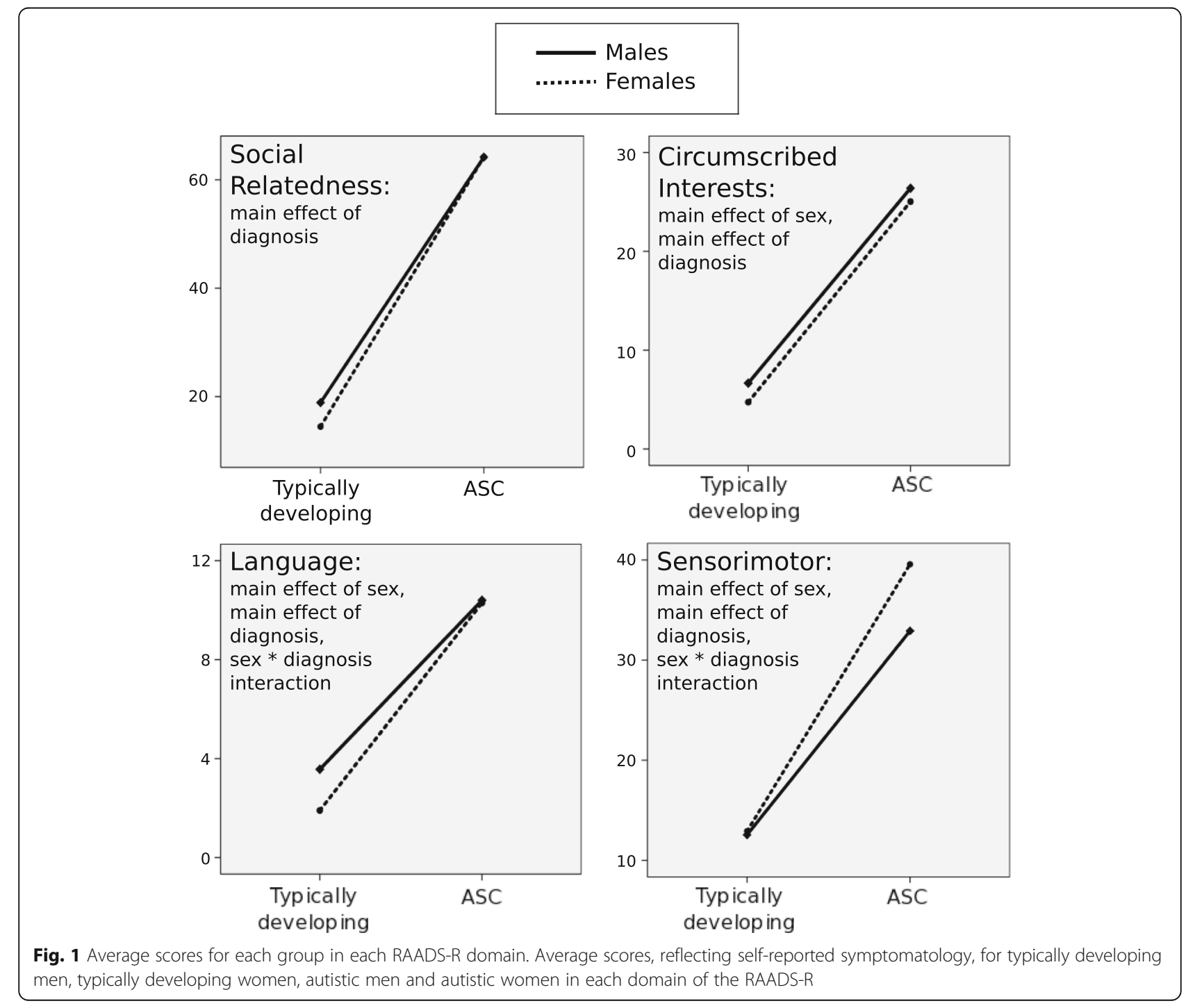


domain, typically developed men scored an average of 18.9 (SD 10.8), typically developing women an average of 14.5 (SD 10.9), autistic men an average of 64.2 (SD 23) and autistic women an average of 64.2 (SD 19.7). A main effect of Diagnosis $(F[1,523]=1068.299, p=.000)$ reflected that autistic participants reported significantly higher prevalence of social problems than typically developed individuals-a finding corroborating the original paper [65] and subsequent validations of the test $[70,71]$. In the same vein, examination of the circumscribed interests domain revealed a main effect of Diagnosis $(F[1,523]=904.268, p<.001)$, with typically developing men and women reporting lower symptoms on average (men 6.7 [SD 4.9], women 4.7 [SD 4. 1]) than autistic men and women (men 26.4 [SD 10.1], women 25 [SD 9.8]). There was also a main effect of Sex $(F$ $[1,523=.6 .080, p=.014)$ reflecting that males generally report more behaviours than women in the circumscribed interests domain.

In the language domain, typically developing men scored on average 3.6 (SD 2.5); women an average 1.9 [SD 1.8]); autistic men an average 10.4 [SD 4.6]; and autistic women an average 10.3 [SD 5.2]. A main effect of Sex $(F[1,523]=$ $7.333, p=.007)$ and a main effect of Diagnosis $(F[1,523]=$ $542.630, p<.001)$ reflected that women generally reported lower scores in autistic language symptomatology than men and that, as expected, individuals with autism reported significantly more symptoms than TD controls. A significant interaction between Sex and Diagnosis $(F[1,523, p=$ 5.707, $p=.017)$ motivated post hoc tests, which revealed that scores differed significantly between typically developing men and women $(t[271]=6.311, p<.001)$ but not between autistic men and women $(p=.866)$.

Highest scores in the sensorimotor domain were seen in autistic women (average 39.6 [SD 12.6]), followed by autistic men (average 32.9 [SD 11.6]), typically developing women (average 12.9 [SD 7.6]) and typically developing men (average 12.5 [SD 7.2]). A significant main effect of Sex $(F[1,523]=16.235, p<.001)$ reflected lower selfreported sensorimotor abnormalities in women, and a main effect of Diagnosis $(F[1,523]=726.807, p<.001)$ reflected greater symptomatology in the autistic group. An interaction between Sex and Diagnosis $(F[1,523, p=.12 .983, p$ $<.001)$, in this domain, reflected a surprising lack of difference between TD men and women $(p=.252)$ and a significant difference between autistic men and women $(t$ [252] $=$ 4.346, $p<.001)$.

\section{Discussion}

For the purpose of early identification, prior investigations of sex differences in autism have predominantly focused on child samples. Given the known difficulty identifying females with autism and the aptitude of many female and male individuals to camouflage their symptoms [32, 34, 35, $58,59,63]$, a substantial unidentified population reach adulthood before being diagnosed [1, 64]. We consequently aimed to extend the small literature on how autistic symptomatology presents in autistic men and women through investigating a commonly used self-report measure, the Ritvo Autism Asperger Diagnostic Scale Revised (RAADS$\mathrm{R}$ [65]). Studying sex differences as and if they emerge in screening instruments may be particularly important if these are considered frontline measures used in triage, as the RAADS-R happens to be in our area. To increase the power of our analysis, we conducted a meta-analysis, gathering data from several research groups. We discuss first the areas in which autistic men and women presented similarly and then the domain in which they differed.

Whilst the now extensive literature on sex differences in autistic children emphasises the divergence between girls and boys, previous investigations in autistic adults have reported similar competence in emotion recognition $[1,53]$ and even the attenuation of normative sex differences in empathising and systemising [53-55]. These findings align with a theoretical perspective that links ASC with the masculinization of brain and behaviour [77-80]. In the domain of social relatedness, we did not find that normative sex differences were attenuated in autism but that autistic men and women were alike in their quantification of symptomology. This is consistent with childhood impairments in the social domain, which appear to be of equal severity in boys and girls [15]. Previous studies have, however, noted a stark divergence between core social understanding and outward expressive social interaction in females [24], which indeed appears to be somewhat more typical due to skilled social mimicry $[5,23,24,33]$. Our data appears to reflect the shared core disability in social understanding, as the social difficulties of autistic women were reported as no less prominent than those of autistic men. A qualitative difference previously reported relating to autistic women's heightened concern over social interaction [63] was not here quantified in reports of greater prevalence of social problems. Of note, however, is the self-report nature of our data: this greater concern over social competence could possibly have served to hide the better expressive social skills evinced in previous studies, if autistic women are inaccurate reporters. As in other studies of sex differences in autistic adults [53], the validity of our self-report measures depends on the selfreflective capacity of participants, differences, or in this case lack of sex differences, thus require independent, objective ratification.

This point holds true when we consider a lack of sex differences between autistic men and women in the circumscribed interests domain, despite a main effect of sex reflecting a general tendency for men to report more symptomatology in this domain. The 'circumscribed interests' domain of the RAADS-R aligns itself with the repetitive 
and restricted behaviours and interest (RRBI) diagnostic criterion [14], including items describing fixated and unusual interests which dominate conversation, detail-level focusing, adherence to fixed routines and difficulties with change, and enjoyment of lists and categorisation. It differs, however, from RRBI as conceptualised in diagnostic instruments such as the ADOS-G [56] and the Autism Diagnostic Interview (ADI-R [81], placing motor stereotypies and stimming (behaviours such as spinning, flicking or twiddling) into the sensorimotor domain. RRBI is the domain where sex differences are most likely to occur in children and young people $[2,5,15]$, with boys showing significantly greater symptomatology. A sex difference in self-reported symptoms in adulthood seems to contradict this finding, but the non-equivalence of 'circumscribed interests' to the RRBI domain makes interpretation somewhat challenging, as RRBI includes sensory and motor abnormalities which we discuss separately below.

In the language domain, an interaction of sex and diagnosis revealed that where normative sex differences appeared between typically developing men and women (perhaps reflecting the commonly held belief of female superiority in communication [82]); there were no statistical differences in the language symptomatology reported by autistic adults. This finding corroborates previous reports of attenuated sex differences in autistic individuals [53-55]. In self-report form, our autistic participants did not corroborate previous suggestions that language skills may be superior in autistic females [5, 21, 24]. We note, however, the rather narrow coverage of the language domain: of these seven items, four relate to literal interpretation of language (e.g. 'The phrase "I've got you under my skin" makes me very uncomfortable'), and only one relates to the ability to engage in reciprocal conversation, which is the area where the camouflage of autistic women serves them well. As such, it is possible that the language measure of the RAADS-R lacks the refinement to pick up a genuine sex difference.

Indeed, at this point, let us further discuss and attempt to interpret the lack of statistical difference between autistic men and women in the social relatedness, circumscribed interests and language domains. The data informs us that autistic women do not rate themselves as significantly more or less symptomatic than men in any one of these domains, but whether these findings reflect a genuine equalisation of childhood differences is equivocal. We have noted, above, the differences that may emerge between studies using self-report data vs. objective observations. A further interpretation of the lack of differentiation seen here and in some other studies of male and female autistics at different ages [11-13] is that it reflects unsuccessful attempts to quantify these differences at domain level [5]. Particularly rich, clinically useful data has come from studies conducting detailed analysis of diagnostic criteria within domains (see Hiller et al. [20] for example). Unfortunately, such scrutiny of individual items was impossible in this metaanalysis where we received only domain scores.

Another interpretation for the lack of differentiation in these domains concerns the diagnostic bottleneck or 'ascertainment bias' $[5,15,22,35,57]$. This and previous studies of the female autistic phenotype are limited by an inherent selection bias in participants. The current conceptualisation of autism, and the diagnostic tools and screening instruments used to detect it, are undeniably androcentric, being developed and standardised according to male cases. The same can be said of the original and revised Ritvo scale, given the heavy male bias in the original and the standardisation sample. As such, when studies examine diagnosed women who could conceivably more closely match the androcentric symptom presentation defined by the tests, similarities to autistic men may be artificially inflated. Studies have attempted to mitigate this problem in several ways: some have included women who do not reach cut-offs in goldstandard tests but whose diagnoses have been confirmed by experience clinicians [53], whereas others have recruited late-diagnosed women whose growing up undiagnosed suggests they did not fit the archetypal presentation of autism [58]. Nevertheless, the potential exclusion of swathes of less stereotypical autistic women casts a modicum of uncertainty on many findings. Future targets for research may be precisely those women referred for diagnosis whom fail to reach cut off on the androcentric instruments of diagnosis but who fulfil criteria for a developmental social and communication disorder on more dimensional scales, such as the Diagnostic Interview for Social and Communication Disorders (DISCO [83]). Here, differences in cognition, emotion and behaviour not only between autistic men and women but between classically diagnosed and subthreshold women might be highly illuminative and reveal a broader female spectrum.

An interesting finding of potential import for diagnosis and conceptualization of autism was the divergence between autistic men and women in the sensorimotor domain. This documents hypersensitivity and extraordinarily negative reactions to the textures of foods and clothes, sounds, noises, lights and being touched by others; hyposensitivity to pain and sensation-seeking behaviours like hand-fiddling, rocking or spinning; experiencing the same sensations as variably too intense or not registering them; and movement coordination problems. ${ }^{1}$ Here, a main effect of sex revealed that females generally reported more sensorimotor differences than males, and a main effect of diagnosis corroborated the established sensorimotor abnormalities associated with autism [84, 85]. An interaction of sex and diagnosis 
revealed, however, that autistic women reported disproportionately more sensorimotor symptoms than their male counterparts. There are extensive reports of sensorimotor abnormalities in autism (see [86, 87] for review), but as usual these are strongly androcentric with few or no female cases. Comparisons with neurotypical peers suggest that motor symptoms are certainly present in autistic girls [88], as are sensory abnormalities [33]; comparisons between males and females on the spectrum, however, are much more scarce. Whilst some imply that sensorimotor abnormalities are equivalent $[27,48]$, one small study using the Japanese version of the CARS [89] found autistic girls between 5 and 9 years of age to show significantly greater abnormality than autistic boys in their responses to taste, smell and touch, and lesser abnormality in their activity level and bodily movements [49]. Interestingly, women generally obtain higher scores than men on this RAADS-R domain, with autistic women reporting the greatest number of symptoms [70]; the same pattern is seen in the 14-item version of the test [71]. Lai et al. [53] created a composite sensory abnormality score from three items of the ADI$\mathrm{R}$ [81] tapping unusual sensory interests, noise hypersensitivity and extraordinarily negative responses to sensory stimuli. According to caregivers who completed the interview, these items were significantly more prevalent in autistic women.

If sensorimotor abnormalities are indeed a more prevalent feature of female autism than, say, the stereotypical manifestation of repetitive and restricted interests $[15,17,24,42-45]$, this finding would have important diagnostic implications. Sensorimotor abnormalities are downplayed in gold-standard diagnostic tests such as the ADOS-G and the ADI-R, which could, in this context, bias the tests away from detecting females. The suggestion must, however, be treated with caution, based as it is on one study with a small sample [49] and one with a measure lacking sensitivity to sensorimotor abnormalities [53]. It has been proposed that autistic women may have greater capacity for self-reflective awareness in symptom reporting $[1,53]$, although in our study they did not rate themselves more symptomatic than men in other domains. In line with the general sex difference in the RAADS-R sensorimotor domain [70], some studies suggest that women are generally more likely to report symptoms they perceive as abnormal and indeed to utilise medical services $[90,91]$, and this may be a normative sex difference that exists in both autistic and nonautistic people. As such, the particular focus that autistic women place on sensorimotor symptoms should be validated by independent, objective measures to investigate whether it has a basis in fact. 'Sensory subtypes' have recently been proposed in childhood autism, although gender did not appear to modulate a child's sensory profile
[92]. With a sample of 203 boys and 25 girls in this study, however, this might be worth investigating in a more balanced child and adult sample.

Alongside the avenues for future research suggested by our findings, the nature of the present study leaves several limitations on which further work could build. Primarily, although we were able to obtain a large dataset from other researchers to compliment the data we obtained from local clinics, we received only scores for each domain (social relatedness, circumscribed interests, language and sensorimotor) as a whole. This lack of scores for individual items within domains precluded other types of analysis, such as those exploring the factor structure of the RAADS-R and potential differences in the same between males and females. The original authors did not focus on sex differences and so reported a factor structure from a heavily maledominated sample. Notably, however, they did report the emergence of a different factor than the sensorimotor one that remains in popular usage of the test: a factor identified as social anxiety. Lacking access to the scores to individual items, we were unable to calculate scores in this alternative domain for our male and female participants-however, it seems highly possible that social anxiety is an area where autistic males and females might diverge, given the suggested greater social motivation of autistic females $[29,30]$.

It is furthermore important to consider the potential influence of several variables which we were unable to control for in the present analysis. Firstly, we unfortunately lacked information regarding psychiatric comorbidities and even additional neurodevelopmental conditions (such as ADHD) in our participants. Whilst neurological conditions were controlled to an extent in some of the data we obtained, we were not privy to information regarding psychiatric comorbidities in any of the participants, thus precluding a more refined analysis. We thus cannot speculate on the effects of psychiatric comorbidities on responses to the RAADS-R (furthermore, we note with interest that the original authors did not appear to screen out additional psychiatric comorbidities in their standardisation sample). This may be highly important, given the greatly elevated prevalence of mental illness in ASC [93], and indeed the high likelihood of autistic females to be misdiagnosed with psychiatric conditions or to come to the attention of clinicians due to other conditions [33].

Race and ethnicity, socioeconomic status and education are other important variables which we were unable to control for in our multi-dataset analysis and which may affect responses to the RAADS-R. The RAADS-R was developed and standardised in Western populations. Although we cannot ascertain the precise ethnicity of each of our participants, it can be surmised with high probability that they were predominantly Caucasian, based on the ethnic diversity of the areas where they 
were recruited. Alongside sex, these are variables which can notably affect symptom presentation and the likelihood of obtaining an ASC diagnosis. In the UK, age of diagnosis is on average earlier in children with highly educated parents from higher socioeconomic backgrounds [94]; in America, autism diagnoses are substantially higher in the higher socioeconomic groups [95-97]. These statistics are explained largely (although not entirely) by another kind of bottleneck or bias in the diagnostic services: that highly educated parents with greater incomes are more likely and more able to approach clinicians with concerns, since many low-income families will lack access to these specialised services. There is, of course, a strong relationship between ethnicity and socioeconomic status. Autistic people from ethnic minority groups are also later to be diagnosed [97-99] and less likely to be diagnosed [97, 100], despite one report of more severe language symptoms in autistic toddlers from minority groups. Culture influences both the manifestation of autistic symptoms $[101,102]$ and their interpretation by parents and other observers [103]. As is typical of autism research in general, the majority of work in this area focuses on children: much less is known about how these variables affect symptom presentation and the likelihood of obtaining a diagnosis in adulthood, and whether they interact with sex, reflecting a clear need for future study.

As concerns sex, genetic evidence suggests a very real possibility that autism may not be equally prevalent in males and females $[2-6,104,105]$. Nevertheless, given their indubitable existence, it is imperative that investigation of the female autistic phenotype remains a high priority, given the suffering reported by late-diagnosed individuals [58, 63]. Maintaining the visibility of this topic is necessary to disseminate this kind of research to professionals within and outside the healthcare fields. A recent, startling finding from Hiller et al. [24] was that the majority of school-age autistic boys had been flagged up by their teachers in the pre-school years, whereas children who had never been a cause for concern were 13 times more likely to be female. The current study furthers investigation of how sex differences present in adulthood, through one screening instrument, the Ritvo Autism Asperger Diagnostic Scale [65]). Our inclusion of a large sample is a strength of the study, but it leaves many openings for future research which should control for psychiatric comorbidities and intellectual function. We may assume from the recruitment techniques and the samples collected (see Additional file 1) that our participants were of average to above-average intelligence. However, the findings cannot speak to the more nuanced issue of how intellectual disability might affect sex differences in autistic symptomatology in adults, and our discussion speaks only to symptom presentation in high- functioning individuals who had completed a self-report measure.

\section{Conclusions}

In these high-functioning individuals, the data from our meta-analysis reveals that autistic women did not statistically differ from autistic men in self-reported symptomatology in domains related to social-relatedness, language and circumscribed interest, but should be ratified by objective measures. It also highlights again the need for research to take into account the so-called ascertainment bias in studying those women who have reached diagnostic cut-offs on androcentric measures, and so whom may plausibly display a more male-like profile. Given the frequent use of child, adolescent and adult screening instruments by diagnostic services, whether these tools can adequately detect more unusual female presentations and subtle camouflaging, as implied in the qualitative literature $[34,35,58]$, is of serious concern. An emergent emphasis by autistic women on their sensorimotor symptoms, however, is of potential clinical relevance, given the traditional downplaying of these items in diagnostic instruments and criteria, and requires further investigation.

\section{Endnotes}

${ }^{1}$ Unusually, four of the twenty items within this domain describe difficulties modulating vocal tone, pitch and volume which in other diagnostic instruments are related rather to differences in language and social communication [56, 81]. The apparent incongruence of these items within this domain is corroborated by the fact that the factor analysis conducted by the original authors [65] found these items loaded instead on factors related to social relatedness and social blindness. The sensorimotor domain, inadequately specific for autism, was subsequently removed from the RAADS-14 [71]

\section{Additional file}

Additional file 1: Details of participant cohorts, meta-analysis procedure. (DOCX $56 \mathrm{~kb}$ )

\section{Abbreviations}

ADI-R: Autism Diagnostic Interview Revised; ADOS-G: Autism Diagnostic Observation Schedule; ASC: Autism spectrum conditions; RAADS-R: Ritvo Autism Asperger Diagnostic Scale Revised; RRBI: Repetitive and restricted behaviours and interest; TD: Typically developing

\section{Acknowledgements}

We would like to acknowledge and thank our colleagues at Bournemouth University for their support, most especially Dr. Bernhard Angele, who provided statistical advice. We would like to thank the students who assisted in TD data collection, Ms. Asia Rose, Ms. Holly Stevens, Ms. Rebecca-Ann Jakeman, and Ms. Lana Gilbert, and all the participants who took part. This study would not have been possible without the assistance of the Community Adult Autism Service in Dorset, for providing us with the Bournemouth autism dataset, and the 
researchers we communicated with, who so generously shared their data with us - we extend our sincerest gratitude to all involved.

\section{Availability of data and materials}

The datasets used and/or analysed during the current study are available from the corresponding author on reasonable request.

\section{Authors' contributions}

Data was collected by all three researchers. Dr. RLM wrote the manuscript, which was edited and contributed to by Dr. JAK and Ms. RH. All authors read and approved the final manuscript.

\section{Ethics approval and consent to participate}

Data collection by the researchers at Bournemouth University was ethically approved by Bournemouth University's ethics panel (for TD controls). The clinic we collaborated with, Dorset NHS Community Adult Asperger Service (CAAS), had previously received NHS approval to collect RAADS-R data. In the course of data collection, participants were told that their data could be used in scientific papers and gave their consent to go forward. The researchers were granted access to raw scores of autistic people but no personal or identifying information, and consent was granted by the clinic for us to publish our findings.

\section{Consent for publication}

Consent to publish data in an anonymous form was obtained from each participant.

\section{Competing interests}

The authors declare that they have no competing interests.

\section{Publisher's Note}

Springer Nature remains neutral with regard to jurisdictional claims in published maps and institutional affiliations.

\section{Received: 19 September 2017 Accepted: 30 April 2018}

\section{Published online: 18 May 2018}

\section{References}

1. Lehnhardt FG, Falter CM, Gawronski A, Pfeiffer K, Tepest R, Franklin J, et al. Sex-related cognitive profile in autism spectrum disorders diagnosed late in life: implications for the female autistic phenotype. J Autism Dev Disord. 2016:46:139-54.

2. Werling DMDM, Geschwind DHDH. Sex differences in autism spectrum disorders. Curr Opin Neurol [Internet] 2013;26:146-153. Available from: http://journals.Iww.com/co-neurology/Abstract/2013/04000/Sex_differences_ in_autism_spectrum_disorders.6.aspx\%5Cn, http://www.pubmedcentral.nih. gov/articlerender.fcgi?artid=4164392\&tool=pmcentrez\&rendertype $=$ abstract

3. Rutherford M, McKenzie K, Johnson T, Catchpole C, O'Hare A, McClure I, et al. Gender ratio in a clinical population sample, age of diagnosis and duration of assessment in children and adults with autism spectrum disorder. Autism [Internet]. 2016;20(5):628-34. Available from: http://www. ncbi.nlm.nih.gov/pubmed/26825959.

4. Loomes R, Hull L, Mandy WPL. What is the male-to-female ratio in autism spectrum disorder? A systematic review and meta-analysis. J Am Acad Child Adolesc Psychiatry [Internet] 2017;56:466-474. Available from: http://www. ncbi.nlm.nih.gov/pubmed/28545751\%0A, http://linkinghub.elsevier.com/ retrieve/pii/S0890856717301521

5. Lai M-C, Lombardo M V., Auyeung B, Chakrabarti B, Baron-Cohen S. Sex/ gender differences and autism: setting the scene for future research. J. Am. Acad. Child Adolesc. Psychiatry [Internet]. Elsevier; 2015 [cited 2014 Dec 18]; 54:11-24. Available from: https://www.jaacap.org/article/508908567(14)00725-4/abstract

6. Sato D, Lionel AC, Leblond CS, Prasad A, Pinto D, Walker S, et al. $<e m>$ SHANK $1</$ em $>$ Deletions in Males with Autism Spectrum Disorder. Am. J. Hum. Genet. [Internet]. 2017;90:879-87. Available from: https://doi. org/10.1016/j.ajhg.2012.03.017

7. Hallmayer J, Cleveland S, Torres A, Phillips J, Cohen B, Torigoe T, et al. Genetic heritability and shared environmental factors among twin pairs with autism. Arch. Gen. Psychiatry [Internet]. 2011 [cited 2014 Jul 26];68: 1095-102. Available from: http://www.ncbinlm.nih.gov/pubmed/21727249

8. Robinson EB, Lichtenstein P. Anckarsater H, Happe F, Ronald A. Examining and interpreting the female protective effect against autistic behavior. Proc
Natl Acad Sci [lnternet]. 2013;110:5258-62. Available from: http://www.pnas. org/cgi/doi/10.1073/pnas.1211070110

9. Ratto AB, Kenworthy L, Yerys BE, Bascom J, Wieckowski AT, White SW, Scarpa A. What about the girls? Sex-based differences in autistic traits and adaptive skills. J Autism Dev Disord. 2018;48(5):1698-1711.

10. Halladay AK, Bishop S, Constantino JN, Daniels AM, Koenig K, Palmer K, et al. Sex and gender differences in autism spectrum disorder: summarizing evidence gaps and identifying emerging areas of priority. Mol Autism. 2015;6:1-5.

11. Andersson GW, Gillberg C, Miniscalco C. Pre-school children with suspected autism spectrum disorders: do girls and boys have the same profiles? Res Dev Disabil. 2013;34:413-22.

12. Fulton AM, Paynter JM, Trembath D. Gender comparisons in children with ASD entering early intervention. Res Dev Disabil. 2017;68:27-34.

13. Postorino V, Fatta LM, De Peppo L, Giovagnoli G, Armando M, Vicari S, et al. Longitudinal comparison between male and female preschool children with autism spectrum disorder. J Autism Dev Disord. 2015;45:2046-55.

14. American Psychiatric Association. Diagnostic and statistical manual of mental disorders (DSM-5 ${ }^{\circ}$ ). Arlington: American Psychiatric Pub; 2013.

15. Van Wijngaarden-Cremers PJM, Van Eeten E, Groen WB, Van Deurzen PA, Oosterling IJ, Van Der Gaag RJ. Gender and age differences in the core triad of impairments in autism spectrum disorders: a systematic review and meta-analysis. J Autism Dev Disord. 2014:627-35.

16. Holtmann M, Bölte S, Poustka F. Autism spectrum disorders: sex differences in autistic behaviour domains and coexisting psychopathology. Dev Med Child Neurol. 2007:49:361-6.

17. Frazier TW, Georgiades S, Bishop SL, Hardan AY. Behavioral and cognitive characteristics of females and males with autism in the Simons Simplex Collection. J Am Acad Child Adolesc Psychiatry. 2014;53(3):329-340.e3.

18. McLennan JD, Lord C, Schopler E. Sex differences in higher functioning people with autism. J Autism Dev Disord [Internet]. 1993;23(2):217-27. Available from: http://link.springer.com/10.1007/BF01046216

19. Begeer S, Mandell D, Wijnker-Holmes B, Venderbosch S, Rem D, Stekelenburg $F$, et al. Sex differences in the timing of identification among children and adults with autism spectrum disorders. J. Autism Dev. Disord. [Internet]. 2013 [cited 2015 Apr 1];43:1151-6. Available from: http://www. ncbi.nlm.nih.gov/pubmed/23001766

20. Giarelli E, Wiggins LD, Rice CE, Levy SE, Kirby RS, Pinto-Martin J, et al. Sex differences in the evaluation and diagnosis of autism spectrum disorders among children. Disabil. Health J. [Internet]. Elsevier Inc; 2010 [cited 2015 Apr 1];3:107-16. Available from: http://www.ncbi.nlm.nih.gov/pubmed/ 21122776

21. Dworzynski K, Ronald A, Bolton P, Happé F. How different are girls and boys above and below the diagnostic threshold for autism spectrum disorders? J. Am. Acad. Child Adolesc. Psychiatry [Internet]. Elsevier Inc; 2012 [cited 2015 Feb 4];51:788-97. Available from: http://www.ncbi.nlm.nih.gov/pubmed/ 22840550

22. Kirkovski M, Enticott PG, Fitzgerald PB. A review of the role of female gender in autism spectrum disorders. J. Autism Dev. Disord. [Internet]. 2013 [cited 2015 Mar 3];43:2584-603. Available from: http://www.ncbi.nlm.nih. gov/pubmed/23525974

23. Rynkiewicz A, Schuller B, Marchi E, Piana S, Camurri A, Lassalle A, et al. An investigation of the "female camouflage effect" in autism using a computerized ADOS-2 and a test of sex/gender differences. Mol. Autism. 2016;7:1-8.

24. Hiller R, Young RL, Weber N. Sex differences in pre-diagnosis concerns for children later diagnosed with autism spectrum disorder. Autism. 2016;20:75-84.

25. Wing L, Gould J. Severe impairments of social interaction and associated abnormalities in children: epidemiology and classification. J Autism Dev Disord. 1979;9:11-29.

26. Kopp S, Gillberg C. Girls with social deficits and learning problems: autism, atypical Asperger syndrome or a variant of these conditions. Eur Child Adolesc Psychiatry. 1992;1:89-99.

27. Rivet TT, Matson JL. Review of gender differences in core symptomatology in autism spectrum disorders. Res. Autism Spectr. Disord. [Internet]. Elsevier Ltd; 2011 [cited 2015 Feb 21];5:957-76. Available from: http://linkinghub. elsevier.com/retrieve/pii/S1750946710001820

28. Wainscot JJ, Naylor P, Sutcliffe P, Tantam D, Williams JV. Relationships with peers and use of the school environment of mainstream secondary school pupils with Asperger syndrome (high-functioning autism): a case-control study. Int J Psychol Psychol Ther. 2008;8:25-38. 
29. Head AM, McGillivray J A, Stokes M A. Gender differences in emotionality and sociability in children with autism spectrum disorders. Mol. Autism [Internet]. Molecular Autism; 2014 [cited 2015 Mar 19];5:19. Available from: http://www.pubmedcentral.nih.gov/articlerender.fcgi?artid=3945617\&tool= pmcentrez\&rendertype $=$ abstract

30. Sedgewick F, Hill V, Yates R, Pickering L, Pellicano E. Gender differences in the social motivation and friendship experiences of autistic and non-autistic adolescents. J Autism Dev Disord. 2016;46:1297-306.

31. Kuo MH, Orsmond Gl, Cohn ES, Coster WJ. Friendship characteristics and activity patterns of adolescents with an autism spectrum disorder. Autism [Internet]. 2013;17:481-500. Available from: http://www.ncbi.nlm.nih.gov/ pubmed/22087043

32. Foggo RSV, Webster AA. Understanding the social experiences of adolescent females on the autism spectrum. Res. Autism Spectr. Disord. 2017:35:74-85.

33. Gould J, Ashton-Smith J. Missed diagnosis or misdiagnosis? Girls and women on the autism spectrum. Good Autism Pract. 2011;12:34-41.

34. Hull L, Petrides KV, Allison C, Smith P, Baron-Cohen S, Lai MC, et al. "Putting on my best normal": social camouflaging in adults with autism spectrum conditions. J Autism Dev Disord. 2017:1-16.

35. Tierney S, Burns J, Kilbey E. Looking behind the mask: social coping strategies of girls on the autistic spectrum. Res Autism Spectr Disord. 2016;23:73-83.

36. Lai M-C, Lombardo M V, Ruigrok AN, Chakrabarti B, Auyeung B, Szatmari P, et al. Quantifying and exploring camouflaging in men and women with autism. Autism [Internet]. 2016;1-13. Available from: http://www.ncbi.nlm. nih.gov/pubmed/27899710

37. Goldman S. Opinion: sex, gender and the diagnosis of autism-a biosocial view of the male preponderance. Res. Autism Spectr. Disord. 2013;7:675-9.

38. Bauminger $\mathrm{N}$, Solomon $\mathrm{M}$, Rogers $\mathrm{SJ}$. Predicting friendship quality in autism spectrum disorders and typical development. J Autism Dev Disord. 2010;40:751-61.

39. Solomon M, Miller M, Taylor SL, Hinshaw SP, Carter CS. Autism symptoms and internalizing psychopathology in girls and boys with autism spectrum disorders. J. Autism Dev. Disord. [Internet]. 2012 [cited 2015 Feb 6];42:48-59. Available from: http://www.pubmedcentral.nih.gov/articlerender.fcgi?artid= 3244604\&tool=pmcentrez\&rendertype=abstract

40. Hiller RM, Young RL, Weber N. Sex differences in autism spectrum disorder based on DSM-5 criteria: evidence from clinician and teacher reporting. J. Abnorm. Child Psychol. [Internet]. 2014 [cited 2015 Feb 4];42:1381-93. Available from: http://www.ncbi.nlm.nih.gov/pubmed/24882502

41. May T, Cornish K, Rinehart N. Does gender matter? A one year follow-up of autistic, attention and anxiety symptoms in high-functioning children with autism spectrum disorder. J Autism Dev Disord. 2014;44:1077-86.

42. Mandy W, Chilvers R, Chowdhury U, Salter G, Seigal A, Skuse D. Sex differences in autism spectrum disorder: evidence from a large sample of children and adolescents. J Autism Dev Disord. 2012:42:1304-13.

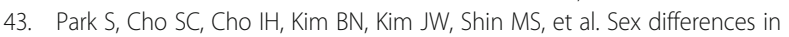
children with autism spectrum disorders compared with their unaffected siblings and typically developing children. Res. Autism Spectr. Disord. [Internet]. 2012;6:861-70. Available from: https://www.sciencedirect.com/ science/article/pii/S1750946711001978.

44. Zwaigenbaum L, Bryson SE, Szatmari P, Brian J, Smith IM, Roberts W, et al. Sex differences in children with autism spectrum disorder identified within a high-risk infant cohort. J. Autism Dev. Disord. [Internet]. 2012;42:2585-96. Available from: http://www.ncbi.nlm.nih.gov/pubmed/22453928

45. Szatmari P, Liu XQ, Goldberg J, Zwaigenbaum L, Paterson AD, WoodburySmith $M$, et al. Sex differences in repetitive stereotyped behaviors in autism: implications for genetic liability. Am J Med Genet Part B Neuropsychiatr Genet. 2012;159 B:5-12.

46. Tillmann J, Ashwood K, Absoud M, Bölte S, Bonnet-Brilhault F, Buitelaar JK, De Bildt A. Evaluating Sex and Age Differences in ADI-R and ADOS Scores in a Large European Multi-site Sample of Individuals with Autism Spectrum Disorder. J Autism Dev Disord. 2018:1-16.

47. Knickmeyer RC, Wheelwright S, Baron-Cohen S. Sex-typical play: masculinization/defeminization in girls with an autism spectrum condition. J Autism Dev Disord. 2008;38:1028-35.

48. Nguyen C, Sc M, Ronald A. How do girls with low functioning autism compare to boys with autism and typically developing girls with regard to behavior, cognition, and psychopathology? Scand J Child Adolesc Psychiatry Psychol [Internet] 2014;2:55-65.
49. Kumazaki H, Muramatsu T, Kosaka H, Fujisawa TX, Iwata K, Tomoda A, et al. Sex differences in cognitive and symptom profiles in children with high functioning autism spectrum disorders. Res Autism Spectr Disord. 2015:13:1-7.

50. Ketelaars MP, In't Velt A, Mol A, Swaab H, Bodrij F, van Rijn S. Social attention and autism symptoms in high functioning women with autism spectrum disorders. Res Dev Disabil. 2017;64:78-86.

51. Klin A, Jones W, Schultz R, Volkmar F, Cohen D. Visual Fixation Patterns During Viewing of Naturalistic Social Situations as Predictors of Social Competence in Individuals With Autism. Arch. Gen. Psychiatry [Internet]. 2002;59:809. Available from: http://archpsyc.jamanetwork.com/article. aspx?doi=10.1001/archpsyc.59.9.809

52. Kliemann D, Dziobek I, Hatri A, Steimke R, Heekeren HR. Atypical reflexive gaze patterns on emotional faces in autism spectrum disorders. J Neurosci [Internet]. 2010;30:12281-7. Available from: http://www.jneurosci.org/cgi/ doi/10.1523/JNEUROSCI.0688-10.2010

53. Lai MC, Lombardo MV, Pasco G, Ruigrok ANV, Wheelwright SJ, Sadek SA, et al. A behavioral comparison of male and female adults with high functioning autism spectrum conditions. PLoS One. 2011;6

54. Lai MC, Lombardo MV, Ruigrok ANV, Chakrabarti B, Wheelwright SJ, Auyeung B, et al. Cognition in males and females with autism: similarities and differences. PLoS One. 2012;7(10):e47198

55. Baron-Cohen S, Cassidy S, Auyeung B, Allison C, Achoukhi M, Robertson S, et al. Attenuation of typical sex differences in 800 adults with autism vs. 3,900 controls. PLoS One. 2014;9(7):e102251.

56. Lord C, Risi S, Lambrecht L, Cook EH, Leventhal BL, Dilavore PC, et al. The autism diagnostic observation schedule-generic: a standard measure of social and communication deficits associated with the spectrum of autism. J Autism Dev Disord. 2000;30:205-23.

57. Bolte S, Duketis E, Poustka F, Holtmann M. Sex differences in cognitive domains and their clinical correlates in higher-functioning autism spectrum disorders. Autism. 2011:15:497-511.

58. Bargiela S, Steward R, Mandy W. The experiences of late-diagnosed women with autism spectrum conditions: an investigation of the female autism phenotype. J Autism Dev Dsorders. 2016;46:3281-94.

59. Hendrickx S. Women and girls with autism spectrum disorder: understanding life experiences from early childhood to old age. London: Jessica Kingsley Publishers; 2015.

60. Kenworthy L, Yerys BE, Anthony LG, Wallace GL. Understanding executive control in autism spectrum disorders in the lab and in the real world. Neuropsychol Rev. 2008;18(4):320-38.

61. Lemon JM, Gargaro B, Enticott PG, Rinehart NJ. Executive functioning in autism spectrum disorders: a gender comparison of response inhibition. J Autism Dev Disord. 2011;41:352-6.

62. Memari AH, Ziaee V, Shayestehfar M, Ghanouni P, Mansournia MA, Moshayedi $P$. Cognitive flexibility impairments in children with autism spectrum disorders: links to age, gender and child outcomes. Res Dev Disabil. 2013;34:3218-25

63. Baldwin S, Costley D. The experiences and needs of female adults with high-functioning autism spectrum disorder. Autism. 2016;20:483-95.

64. Lai MC, Baron-Cohen S. Identifying the lost generation of adults with autism spectrum conditions. The Lancet Psychiatry. 2015;2(11):1013-27.

65. Ritvo RA, Ritvo ER, Guthrie D, Ritvo MJ, Hufnagel DH, McMahon W, et al. The Ritvo Autism Asperger Diagnostic Scale-Revised (RAADS-R): a scale to assist the diagnosis of autism spectrum disorder in adults: an international validation study. J Autism Dev Disord. 2011;41:1076-89.

66. Van Casteren $M$, Davis MH. Match: a program to assist in matching the conditions of factorial experiments. Behav Res Methods. 2007;39:973-8.

67. National Institute of Health and Care Excellence. Autism spectrum disorder in adults: diagnosis and management [Internet]. NICE Guidel. 2012 [cited 2017 Dec 30]. Available from: https://www.nice.org.uk/guidance/cg142/ chapter/1-guidance

68. Stoesz BM, Montgomery JM, Smart SL, Hellsten L-AM. Review of five instruments for the assessment of Asperger's disorder in adults. Clin Neuropsychol [Internet] 2011;25:376-401. Available from: http://www. informaworld.com/smpp/title content=t713721659\%5Cnhttp://dx.doi.org/ 10.1080/13854046.2011.559482\%5Cn, http://www.informaworld.com/\%5Cn, http://www.psypress.com/tcn

69. Frazier TW, Ratliff KR, Gruber C, Zhang Y, Law P A, Constantino JN. Confirmatory factor analytic structure and measurement invariance of quantitative autistic traits measured by the Social Responsiveness Scale-2. 
Autism [lnternet]. 2014;18:31-44. Available from: http://www.ncbi.nlm.nih. gov/pubmed/24019124

70. Andersen LMJ, Näswall K, Manouilenko I, Nylander L, Edgar J, Ritvo RA, et al. The Swedish version of the Ritvo Autism and Asperger Diagnostic Scale: Revised (RAADS-R). A validation study of a rating scale for adults. J Autism Dev Disord. 2011:41:1635-45.

71. Eriksson JM, Andersen LM, Bejerot S. RAADS-14 Screen: validity of a screening tool for autism spectrum disorder in an adult psychiatric population. Mol. Autism [Internet]. 2013;4:49. Available from: http://www. pubmedcentral.nih.gov/articlerender.fcgi?artid=3907126\&tool= pmcentrez\&rendertype $=$ abstract

72. American Psychiatric Association. Diagnostic and statistical manual of mental disorders (4th Edition, Revision). Fourth. Washington, DC: American Psychiatric Association; 2000 .

73. Organization WH. The ICD-10 classification of mental and behavioural disorders: clinical descriptions and diagnostic guidelines. World Health Organization [Internet]. 1992;1-267. Available from: http://apps.who.int/iris/ handle/10665/37958\%5Cn, http://scholar.google.com/scholar?hl=en\&btnG= Search\&q=intitle:The+ICD-10+Classification+of+Mental+and+Behavioural +Disorders\#1

74. Field AP, Gillett R. How to do a meta-analysis. Br J Math Stat Psychol. 2016; 63:665-94.

75. Vagni D, Moscone D, Travaglione S, Cotugno A. Using the Ritvo Autism Asperger Diagnostic Scale-Revised (RAADS-R) disentangle the heterogeneity of autistic traits in an Italian eating disorder population. Res. Autism Spectr. Disord. 2016;32:143-55.

76. Satterfield D, Lepage $C$, Ladjahasan N. Preferences for online course delivery methods in higher education for students with autism spectrum disorders. Procedia Manuf. 2015;3

77. Baron-Cohen. The extreme male brain theory of autism. Trends Cogn. Sci. [Internet]. 2002;6:248-54. Available from: https:/www.ncbi.nlm.nih.gov/pubmed/ 12039606

78. Baron-Cohen S, Baron-Cohen S. The hyper-systemizing, assortative mating theory of autism. Prog Neuro-Psychopharmacol Biol Psychiatry. 2006;30(5): 865-72. Prog. Neuro-Psychopharmacology Biol. Psychiatry. 2006;30:865-72

79. Baron-Cohen S, Auyeung B, Nørgaard-Pedersen B, Hougaard DM, Abdallah MW, Melgaard L, et al. Elevated fetal steroidogenic activity in autism. Mol. Psychiatry [Internet]. 2015;20:369-76. Available from: http://www.ncbi.nlm. nih.gov/pubmed/24888361

80. Auyeung B, Taylor K, Hackett G, Baron-Cohen S. Foetal testosterone and autistic traits in 18 to 24-month-old children. Mol Autism. 2010;1:11.

81. Le Couteur A, Lord C, Rutter M. The autism diagnostic interview-revised (ADI-R). Los Angeles: Western Psychological Services; 2003.

82. Wallentin M. Putative sex differences in verbal abilities and language cortex: a critical review. Brain Lang. 2009;108:175-83.

83. Wing L, Leekam SR, Libby SJ, Gould J, Larcombe M. The diagnostic interview for social and communication disorders: background, inter-rater reliability and clinical use. J Child Psychol Psychiatry Allied Discip. 2002;43: $307-25$

84. Klintwall L, Holm A, Eriksson M, Carlsson LH, Olsson MB, Hedvall Å, et al. Sensory abnormalities in autism. A brief report. Res Dev Disabil. 2011;32: 795-800.

85. Marco EJ, Hinkley LBN, Hill SS, Nagarajan SS. Sensory processing in autism: a review of neurophysiologic findings. Pediatr Res. 2011;69

86. Fournier KA, Hass CJ, Naik SK, Lodha N, Cauraugh JH. Motor coordination in autism spectrum disorders: a synthesis and meta-analysis. J Autism Dev Disord. 2010;40:1227-40.

87. Moseley RL, Pulvermüller F. What can autism teach us about the role of sensorimotor systems in higher cognition? New clues from studies on language, action semantics, and abstract emotional concept processing. Cortex. 2018;100:149-190

88. Kopp S, Beckung E, Gillberg C. Developmental coordination disorder and other motor control problems in girls with autism spectrum disorder and/or attention-deficit/hyperactivity disorder. Res Dev Disabil. 2010;31:350-61.

89. Schopler E, Van Bourgondien ME, Wellman GJ, Love SR. The childhood autism rating scale. Los Angeles: WPS; 1980.

90. Ladwig KH, Marten-Mittag B, Formanek B, Dammann G. Gender differences of symptom reporting and medical health care utilization in the German population. Eur J Epidemiol. 2000;16:511-8.

91. Green CA, Pope CR. Gender, psychosocial factors and the use of medical services: a longitudinal analysis. Soc Sci Med. 1999;48:1363-72.
92. Lane AE, Molloy CA, Bishop SL. Classification of children with autism spectrum disorder by sensory subtype: a case for sensory-based phenotypes. Autism Res. 2014;7:322-33.

93. Croen LA, Zerbo O, Qian Y, Massolo ML, Rich S, Sidney S, et al. The health status of adults on the autism spectrum. Autism [Internet]. 2015;19:814-23. Available from: http://www.ncbi.nlm.nih.gov/pubmed/25911091

94. Fountain C, King MD, Bearman PS. Age of diagnosis for autism: individual and community factors across 10 birth cohorts. J Epidemiol Community Health. 2011;65:503-10.

95. Croen LA, Grether JK, Selvin S. Descriptive epidemiology of autism in a California population: who is at risk? J Autism Dev Disord. 2002;32:217-24.

96. Durkin MS, Maenner MJ, Meaney FJ, Levy SE, di Guiseppi C, Nicholas JS, et al. Socioeconomic inequality in the prevalence of autism spectrum disorder: evidence from a U.S. cross-sectional study. PLoS One. 2010;5

97. Thomas P, Zahorodny W, Peng B, Kim S, Jani N, Halperin W, et al. The association of autism diagnosis with socioeconomic status. Autism [Internet]. 2012;16:201-13. Available from: http://journals.sagepub.com/doi/ 10.1177/1362361311413397

98. Mandell DS, Novak MM, Zubritsky CD. Factors associated with age of diagnosis among children with autism spectrum disorders. Pediatrics [Internet]. 2005;116:1480-6. Available from: http://www.ncbi.nlm.nih.gov/ pubmed/16322174\%5Cn, http://www.pubmedcentral.nih.gov/articlerender. fcgi?artid=PMC2861294

99. Mandell DS, Listerud J, Levy SE, Pinto-Martin JA. Race differences in the age at diagnosis among Medicaid-eligible children with autism. J. Am. Acad. Child Adolesc. Psychiatry [Internet]. 2002:41:1447-53. Available from: http:// www.sciencedirect.com/science/article/pii/S0890856709607395

100. Begeer S, Bouk S El, Boussaid W, Terwogt MM, Koot HM. Underdiagnosis and referral bias of autism in ethnic minorities. J Autism Dev Disord 2009;39:142-148.

101. Matson JL, Worley JA, Fodstad JC, Chung K-M, Suh D, Jhin HK, et al. A multinational study examining the cross cultural differences in reported symptoms of autism spectrum disorders: Israel, South Korea, the United Kingdom, and the United States of America. Res. Autism Spectr. Disord. [Internet]. 2011;5:1598-604. Available from: http://linkinghub.elsevier.com/ retrieve/pii/S1750946711000705

102. Matson JL, Matheis M, Burns CO, Esposito G, Venuti P, Pisula E, et al. Examining cross-cultural differences in autism spectrum disorder: a multinational comparison from Greece, Italy, Japan, Poland, and the United States. Eur Psychiatry. 2017;42:70-6.

103. Ennis-Cole D, Durodoye BA, Harris HL. The impact of culture on autism diagnosis and treatment: considerations for counselors and other professionals. Fam J Couns Ther Couples Fam. 2013;21:279-87.

104. Hallmayer J, Cleveland S, Torres A, Phillips B, Torigoe T, Miller J, et al. Genetic heritability and shared environmental factors among twin pairs with autism. Arch. Gen. Psychiatry [Internet]. 2011;68:1095. Available from: http://archpsyc.jamanetwork.com/article.aspx?doi=10.1001/ archgenpsychiatry.2011.76

105. Robinson EB, Lichtenstein P, Anckarsäter H, Happé F, Ronald A. Examining and interpreting the female protective effect against autistic behavior. Proc. Natl. Acad. Sci. U. S. A. [Internet]. 2013;110:5258-62. Available from: http:// www.pubmedcentral.nih.gov/articlerender.fcgi?artid=3612665\&tool= pmcentrez\&rendertype=abstract

\section{Ready to submit your research? Choose BMC and benefit from:}

- fast, convenient online submission

- thorough peer review by experienced researchers in your field

- rapid publication on acceptance

- support for research data, including large and complex data types

- gold Open Access which fosters wider collaboration and increased citations

- maximum visibility for your research: over $100 \mathrm{M}$ website views per year

At BMC, research is always in progress.

Learn more biomedcentral.com/submissions 